\title{
EDUCAÇÃO AMBIENTAL: PRÁTICAS SUSTENTÁVEIS NA CONSTRUÇÃO CIVIL
}

\author{
ENVIRONMENTAL EDUCATION: SUSTAINABLE PRACTICES IN CIVIL \\ CONSTRUCTION
}

\author{
Adelania de Oliveira Souza ${ }^{1}$ \\ Thalita Maria Ramos Porto ${ }^{2}$ \\ Guilherme Urquisa Leite ${ }^{3}$ \\ Hellykan Berliet dos Santos Monteiro ${ }^{4}$ \\ Fernando Chagas de Figueiredo Sousa ${ }^{5}$ \\ Maria Aparecida Bezerra Oliveira ${ }^{6}$
}

\footnotetext{
${ }^{1}$ Graduanda em Engenharia Civil pela Faculdade Santa Maria - FSM.

${ }^{2}$ Engenheira civil (2015), formada pela Universidade federal de Campina Grande- UFCG. Atuei como engenheira júnior no ano de 2016 na Construtora Norte Nordeste ME Ltda, realizando fiscalização e gerenciamento de obras. Mestre (2018) em Engenharia Civil e Ambiental (PPGECA? UFCG) e Doutoranda em Engenharia Civil e Ambiental pela UFCG. Sou professora desde 2016, lecionei em instituições de ensino técnico como Grau Técnico e Infogenius, responsável por disciplinas nas áreas da construção civil. Atualmente, sou professora com dedicação exclusiva na Faculdade Santa Maria, lecionando disciplinas direcionadas ao curso de engenharia civil, de nível profissional. Também atuo na Faculdade Santa Maria como coordenadora de estágio do curso de engenharia civil.

${ }^{3}$ Possui graduação em Engenharia Civil pela Universidade Federal da Paraíba (2011) e mestrado em Engenharia Civil e Ambiental pela Universidade Federal da Paraíba (2016). Atualmente é docente do curso de bacharelado em Engenharia Civil da Faculdade Santa Maria, responsável pelas unidades curriculares de Eletrotécnica, Instalações Elétricas Prediais, Instalações Hidrossanitárias, Estradas e Transporte I e II e Concreto Protendido e Pré-moldado.

${ }_{4}^{4}$ Possui graduação em Engenharia Civil pela Universidade Federal de Campina Grande (UFCG/ 2014), Mestrado em Estruturas com ênfase em materiais de construção pelo Programa de PósGraduação em Engenharia Civil (PPGEC/ 2017) da Universidade Federal de Pernambuco. Trabalha como Professora na Faculdade Santa Maria - FSM, é responsável pelas unidades curriculares de estruturas de concreto armado, resistência dos materiais I e estática das construções I e estruturas metálicas e de madeira.

${ }^{5}$ Engenheiro Civil graduado pela Universidade Federal de Campina Grande - UFCG, Epecialista em Perícia Ambiental, Mestre em Sistemas Agroindustriais (UFCG), com atuação profissional na área de Construção Civil (Acompanhamento e perícia) e de geotecnia (estradas e rodovias). Professor da Faculdade Santa Maria, Cajazeiras - PB, responsáveis pelas unidades curriculares de construção civil, planejamento de obras, introdução ao bim e projeto arquitetônico.

${ }^{6}$ Possui graduação em Ciência e Tecnologia e em Engenharia Civil pela Universidade Federal Rural do Semi-Árido - UFERSA (2011-2016). Especialista em docência do ensino superior (2017-2018) pela Faculdade Santa Maria. Mestrado em Sistemas Agroindustriais com linha de pesquisa em recursos hidricos e saneamento ambiental (2017) Pela Universidade Federal de Campina Grande-UFCG. Docente no curso de Graduação em Engenharia Civil da Faculdade Santa Maria - Cajazeiras - PB. Atua na área de Resíduos Sólidos e Recursos Hidricos, é responsável pelas unidades curriculares de materiais de construção civil II, introdução a engenharia civil e eletrotécnica geral.
} 
RESUMO: O estudo será do tipo bibliográfico e exploratório com estudo de campo in loco, visitas a órgãos e escolas municipais locais e se desenvolverá na cidade de Cajazeiras-PB. A proposta é a criação de uma estufa sustentável para cultivo de hortaliças, com resíduos sólidos recicláveis descartados no meio ambiente e que podem ser reutilizados na construção. A princípio, eles devem ser identificados e analisados, a fim de apresentar as mesmas características dos materiais não convencionais na construção de uma estufa original. Realizou-se um levantamento quantitativo financeiro de materiais feito em empresas do comércio local, para traçar o comparativo de custo estimado dos materiais diversos empregados na construção. Com a análise, podem-se comparar as vantagens e o custo-benefício para aquisição de uma estufa de hortas urbanas confeccionada com material não convencional, aplicando o processo de reciclagem, no qual se sugere a reutilização de materiais descartados no meio ambiente. Com a realização de pesquisa de preços das empresas (A) e (B) das tabela 03 e 04, obteve-se um preço total de $R \$ 142,86$ e $R \$$ 157,96 , respectivamente, esses valores são equivalente para execução de $1 \mathrm{~m}^{2} \mathrm{de}$ estufa com material não convencional. Assim, por meio da realização de um do orçamento comparativo, levando em conta a disponibilidade de materiais e mão de obra na região, e após uma análise obteve-se uma redução de custos financeiros, sendo viável a execução e emprego da estufa sustentável nas escolas municipais da cidade de Cajazeiras-PB. Logo, após avaliação da estufa, observa-se que houve uma grande economia de materiais e mão de obra, além da redução de resíduos sólidos proporcionado pela reutilização dos mesmos. Ressalta-se que a estruturação da estufa sustentável proposta a ser seguida na construção pode ser empregada em qualquer região, pois o foco está mantido na reutilização dos materiais não convencionais, visto que a produção de resíduos sólidos é um problema de contexto mundial.

Descritores: Conscientização. Desenvolvimento regional. Materiais Recicláveis. Sustentabilidade.

ABSTRACT: The study will be of the bibliographic and exploratory type in loco, with visits to local agencies and municipal schools and developed in the city of Cajazeiras-PB. The proposal is the creation of a sustainable greenhouse cultivation of vegetables, with recyclable solid waste disposed in the environment and that can be reused in the construction. In principle, they should be identified and analyzed, in order to present the same characteristics of non-conventional materials in the construction of a greenhouse. A quantitative survey of materials was conducted in companies of local trade, to draw the comparison of estimated cost of various materials used in construction. With the analysis, one can compare the advantages and the cost-benefit ratio for the acquisition of a greenhouse of urban gardens made with non-conventional material, applying the recycling process, which suggests the reuse of materials disposed in the environment. With the completion of survey of prices of companies $(A)$ and $(B)$ of Table 03 and 04 , the total price was of $R \$ 142.86$ and $R \$ 157.96$, respectively, values equivalent to execution of $1 \mathrm{~m}^{2}$ of a greenhouse with non-conventional material. Thus, through the completion of a comparative 
budget, taking into account the availability of materials and labor in the region, and after an analysis, there was a reduction of financial costs, being feasible the implementation and use of sustainable greenhouse in municipal schools of the city of Cajazeiras-PB. Therefore, after evaluation of the greenhouse, there was a large economy of materials and labor, in addition to the reduction of solid waste provided by reusing the same. The structuring of the sustainable greenhouse proposal to be followed in the construction may be employed in any region, because the focus is to keep the reuse of non-conventional materials, since the production of solid waste is a problem of global context.

Descriptors: Awareness. Regional development. Recyclable materials. Sustainability. 


\section{INTRODUÇÃO}

A Educação Ambiental é tema de discussões nas últimas décadas. Esse termo remete, de maneira geral, a um cuidado necessário e primordial com o meio ambiente, porém ainda é um grande desafio para o planeta, pois a sociedade como um todo não é conscientemente educada para cuidar e proteger o meio em que vive de maneira a conservar os recursos naturais presentes (MELLO, 2017).

De acordo com Morales (2004), a Educação Ambiental é a condição básica para alterar um quadro crítico, perturbador e desordenado, recheado de crescente degrada4ção socioambiental, mas que só ela não é suficiente para tanto. Assim, a educação ambiental é importante no contexto sociocultural, a mediação entre a relação sociedade $\mathrm{x}$ natureza, buscando construir uma sociedade sustentável que privilegie a racionalidade e o saber socioambiental.

A educação formal tem por objetivo desenvolver cidadãos capazes de refletir sobre os problemas de modo geral, criando condições para que ocorra uma aprendizagem voltada para a Educação Ambiental. Ressalta-se que seu papel junto a Educação Ambiental é integrar os seres humanos e a conservação do meio ambiente (DIAS, 2004). Dessa maneira, os gestores das cidades devem promover a gestão participativa da sociedade, através de apoio ou realização de programas de ações socioeducativas ligados ao meio ambiente, uma conscientização. $E$ isso ocorre pela educação não formal, a qual não resolve todos os problemas ambientais e nem salva completamente o planeta, mas irá criar o respeito e a visão de que devemos cuidar e proteger o meio ambiente, para as gerações atuais e futuras, além de colaborar para o desenvolvimento sustentável local.

Com base em dados disponíveis pela Divisão de Fiscalização (DIFI), na cidade de João Pessoa, capital do estado paraibano, até 30 de março de 2018, já foram registrado em torno de 1.152 denúncias de possíveis crimes ambientais, envolvendo queixas relacionadas à poluição sonora, atmosférica, desmatamento e lançamento de esgoto no meio de ruas. (Secretaria de Meio Ambiente -SEMAM, 2018). 
Diariamente, vivenciam-se crimes ambientais, como o consumo e exploração dos recursos naturais que ocorrem cada vez mais desenfreados, contaminação de rios e geração de resíduos sólidos e outros componentes não degradáveis que causam danos irreversíveis ao meio ambiente (MELLO, 2017). Sabe-se que a construção civil também é um dos elementos que mais influenciam nas causas desses problemas. Sendo assim, é importante tentar desenvolver uma sociedade justa, com uma economia viável e ambientalmente correta. Esse estudo aponta para uma preocupação que norteia a pesquisa, tendo como problema principal a seguinte questão: Como a Educação Ambiental pode ser impulsionadora do desenvolvimento na cidade de Cajazeiras - PB, por meio de práticas sustentáveis na construção civil?

A importância desse estudo torna-se necessária para melhorar a relação homem/ natureza, por meio da conscientização da sociedade local com uma educação não formal, transformando a realidade encontrada e gerando melhores resultados para o mundo, para formar cidadãos ativos que saibam identificar os problemas e participar efetivamente de soluções e prevenções (CARVALHO, 2012). Mediante a isso, a construção civil é uma atividade que promove desenvolvimento social e econômico, porém utiliza grandes quantidades de recursos naturais e promove a geração em grandes quantidades de resíduos sólidos, havendo assim, a necessidade de desenvolver novas práticas visando à sustentabilidade.

Assim, esse trabalho consiste numa contribuição para fortalecimento no que diz respeito a superar os desafios e as possibilidades que envolvem a questão ambiental do município de Cajazeiras - PB, servindo como base para fortalecer os projetos de educação ambiental que já estão sendo desenvolvidos e também, para aqueles que tiverem interesse em se aprofundar mais nessa temática. Logo, proporcionará mais enriquecimento no que se refere a como desenvolver práticas que contribuam para uma melhor conservação do meio ambiente, por meio da troca de informações e ideias, seja nas salas de aula, em palestras, em campo, entre outros. Afinal, tratar do meio ambiente e da Educação Ambiental, nas perspectivas multidisciplinar, interdisciplinar e transdisciplinar, contribui para um desenvolvimento sustentável equilibrado. 


\section{METODOLOGIA}

A pesquisa sucedeu-se na cidade de Cajazeiras-PB, localizada na mesorregião do Alto Sertão paraibano, a uma distância de 468 km de João Pessoa, capital do Estado, e ocupa uma área territorial de 565. $889 \mathrm{~km}^{2}$ (RODRIGUES, 2002).

O trabalho respaldou-se, inicialmente, em uma pesquisa bibliográfica com a realização de uma fundamentação de informações em trabalhos impressos e eletrônicos, como livros, teses, dissertações, etc. de autores e pesquisadores renomados que discutem a respeito da Educação Ambiental e práticas sustentáveis na construção civil. Esta etapa possibilitará a construção da base necessária para o entendimento histórico da Educação Ambiental a nível mundial, regional e local e os estudos já dirigidos a respeito da temática proposta por esta pesquisa.

Em paralelo, evidenciou-se uma pesquisa exploratória que se dará através dos estudos de campo in loco, com visitas que serão efetivadas aos órgãos do município, como as Secretarias de Desenvolvimento Rural e do Meio Ambiente, três Escolas Municipais de Ensino Infantil e Fundamental, as quais serão a Escola Antônio de Souza Dias, localizada no Sítio Cocos, Escola Costa e Silva, no bairro Jardim Oásis e a Escola Luiz Cartaxo Rolim, no bairro da Esperança, e por fim, será visitada a Organização da Sociedade Civil de Interesse Público Luiz Antônio Bezerra - OSCIP, situada no bairro dos Remédios (Ver figura 04).

A proposta é a criação de uma estufa sustentável para cultivo de hortaliças, com resíduos sólidos recicláveis descartados no meio ambiente e que podem ser reutilizados na construção. A princípio, eles devem ser identificados e analisados, a fim de apresentar as mesmas características dos materiais não convencionais na construção de uma estufa original.

Para a proposta, estimam-se as seguintes características gerais, conforme figura 01, para serem desenvolvidas com materiais convencionais e comparada em relação ao custo financeiro de outra estufa de materiais não convencionais. 
Figura 01: Determinações das características gerais da estufa.

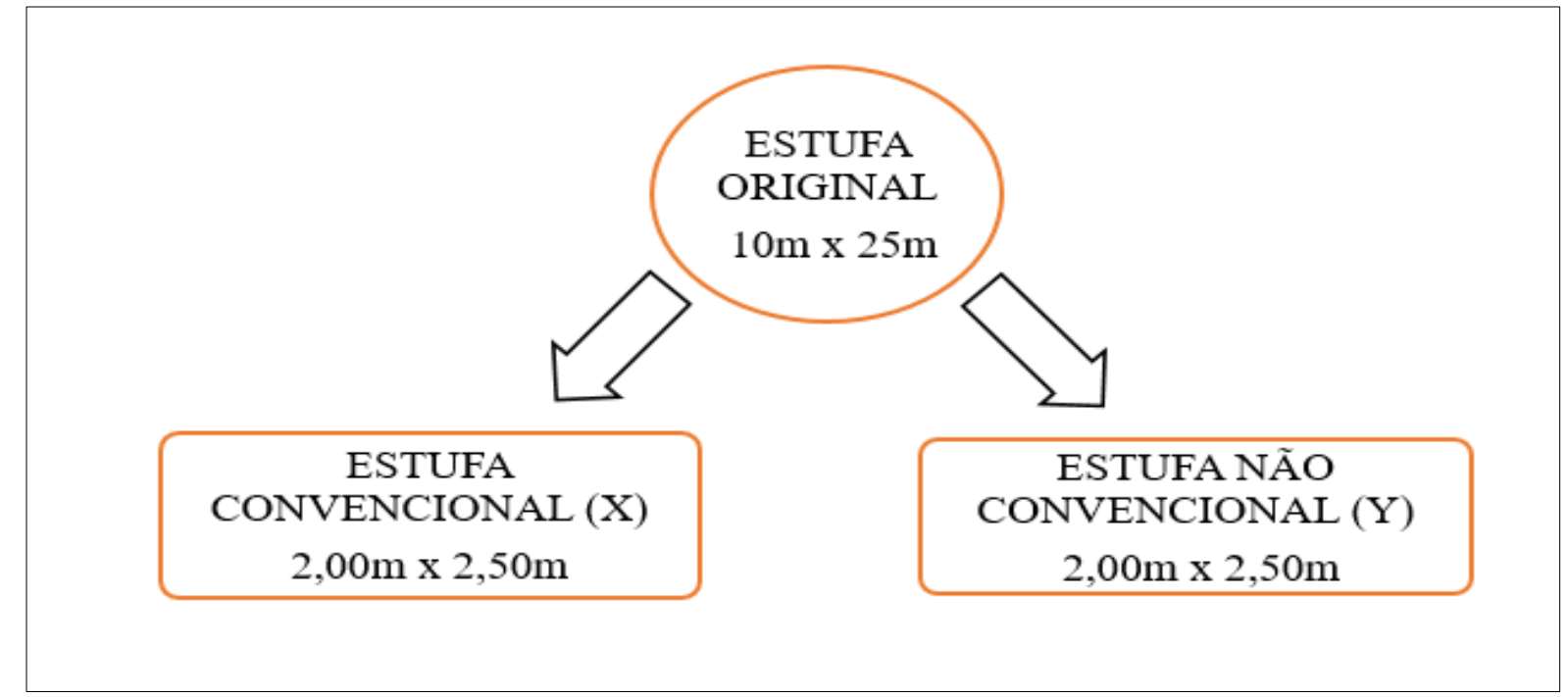

Fonte: SOUZA,2019.

Em seguida, realiza-se um levantamento quantitativo financeiro de materiais feito em empresas do comércio local, para traçar o comparativo de custo estimado dos materiais diversos empregados na construção. Com a análise, podem-se comparar as vantagens e o custo benefício para aquisição de uma estufa de hortas urbanas confeccionada com material não convencional, aplicando o processo de reciclagem, no qual se sugere a reutilização de materiais descartados no meio ambiente. Propõe-se que a estufa sustentável a ser inserida no Projeto Civil Verde seja construída com dimensões de 2,50 m de comprimento por 2,00 m de largura totalizando uma área de $5 \mathrm{~m}^{2}$ e empregue-se a reutilização e a reciclagem de resíduos sólidos de obras, madeireiras e residências familiares. Destaca-se a utilização de materiais que foram descartados após o uso, sendo doados para serem reutilizados.

Os layouts da estufa proposta foram criados no software Auto cad 2017, corte e fachadas necessários para melhor compreensão da estufa proposta. Em seguida, orienta-se sobre o passo a passo a ser seguido para a construção futura da estufa dentro do projeto civil verde. Conforme as etapas a seguir: serviços preliminares, escavação e construção e por fim, cobertura e finalização. 
Preliminarmente, tem de se determinar o local de implantação, visando a uma área satisfatória de modo a agregar condicionantes favoráveis para a construção e viabilidade da estufa. A construção da estufa visa à reutilização de materiais convencionais. Os resíduos sólidos para execução são RCDs, madeiras e plásticos, coletados na cidade de Cajazeiras-PB. Esses materiais podem ser reutilizados agregando valor econômico ao protótipo, reduzindo a poluição e contaminação do meio ambiente.

A sugestão dada de terreno escolhido para implantá-la deve possuir uma superfície plana, livre de vegetações, com índices de ventilação reduzida. Posteriormente, necessita-se realizar a demarcação do terreno conforme as dimensões estabelecidas, destacando a efetivação do enquadramento e nivelamento da área de acordo com o projeto proposto.

Nessa etapa, marcam-se os pontos necessários para a alocação das colunas

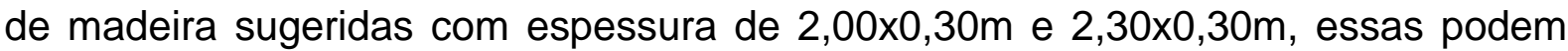
ser fixadas por cravação de eixo a eixo, com distância de 1,25 m no sentindo maior. A madeira utilizada tem uma parte cravada no solo a uma profundidade de $0,30 \mathrm{~m}$, passa por um tratamento histórico e regular da região para proteger contra os microrganismos deterioradores de madeira como cupim e outros agentes biológicos que possam vir a causar problemas na madeira, sendo assim indicada a reutilização de óleo descartado em oficinas mecânicas para proteção do madeiramento. Inicialmente, passam-se duas demãos do óleo diesel e, posteriormente, cobre-se com material plástico, utilizando sacolas plásticas. Assim, quando a madeira está em contato com o solo, dispõe de mais durabilidade.

Em seguida, escavam-se valas com 0,10 m de profundidade e 0,30 $\mathrm{m}$ de largura para marcação da área, sendo essas preenchidas com agregado graúdo retido na peneira 1" e 3/4'", com malhas $25 \mathrm{~mm}$ e $19 \mathrm{~mm}$ respectivamente, provenientes de corpos de provas do laboratório de Técnicas Construtivas da Faculdade Santa Maria (FSM), os corpos de prova passaram pelo processo de moagem em um triturador de mandíbulas, os resíduos gerados após a moagem foram empregados para delimitação da área da estufa (base). Logo após a distribuição desse material na vala, realiza-se a compactação para um nivelamento e ajuste do mesmo. 
Esta etapa refere-se à cobertura da estufa realizada para proteger a área das intempéries do tempo. A estrutura do telhado sugerida é do tipo "1 queda d'água", apresentando inclinação apenas em um sentido. Para o telhado usa-se ripas de $1,20 \times 0,15 \times 0,25 \mathrm{~m}$, originárias de excessos de madeireiras e com garrafas PET de 2 litros provenientes de refrigerantes. Cria-se uma estrutura de garrafa pet fixada nas ripas com grampeador de parede. Ressalta-se que, para usar a garrafa pet, precisase que se retire o gargalho, fundo e trabalhar com ela aberta. Com essa abertura, forma-se uma folha retangular com dimensões de $0,20 \times 0,30 \mathrm{~m}$, em seguida uniramse quatro para atender a uma área maior.

\section{RESULTADOS}

A política no município de Cajazeiras é para ser desenvolvida através da Secretaria Executiva de Meio Ambiente-SEMAC, conforme contato com a gestora dessa secretaria. O município de Cajazeiras, como a maioria dos municípios paraibanos, não apresenta uma estrutura mínima necessária para o funcionamento efetivo da gestão ambiental municipal, quadro real dos municípios brasileiros, como reflexo do desenvolvimento de uma gestão ambiental centralizada desde os seus primórdios. Apesar de ter criado legalmente o órgão municipal de meio ambiente, o conselho municipal de meio ambiente, o fundo municipal de meio ambiente e o código municipal de meio ambiente, na prática essa estrutura não funciona como deveria. Nesse sentido, não existe ativamente uma política municipal de Educação Ambiental em desenvolvimento, que possa atender o campo formal e informal. $O$ que existe são ações pontuais de participação e envolvimento de setores quando solicitado.

Atualmente, o sistema municipal responsáveis pela gestão ambiental do município de Cajazeiras-PB encontra-se em desenvolvimento. A cidade possui a Secretaria de Desenvolvimento Rural e Meio Ambiente (SEDRUMA) unificada, ou seja, dois órgãos juntos para atender as necessidades da cidade e seus distritos. A administração municipal vem tentando melhorar as condições para mudar essa 
realidade e tornar esse órgão, um verdadeiro ator da gestão ambiental local, visto sua importância para o desenvolvimento sustentável do município.

Com base nisso, notamos que a gestão municipal ambiental não ocorre ativamente como deveria, impedindo uma maior interação entre sociedade e gestão ambiental, a ponto de não propiciar momentos e espaços para essa interação. Também se encontra como um dos desafios da gestão ambiental a pouca participação da sociedade na gestão ambiental municipal, apresentando no seu desenvolvimento condicionantes e limites que dificultam essa participação, são exemplos a falta de informação, a falta de capacitação para compreensão das questões ambientais locais, o distanciamento histórico do homem em relação à natureza vinculado ao modelo de desenvolvimento capitalista que fez com que a natureza fosse vista como mera fornecedora de matéria prima para o progresso da sociedade.

O município apresenta pequeno índice de "sustentabilidade", pois diante do histórico relatado, fica difícil dizer que existem ações desenvolvidas continuamente em busca de um futuro localmente sustentável. Espera-se que, aos poucos, por meio do avanço e desenvolvimento da SEDRUMA, possa-se mudar essa realidade.

O Civil Verde é um projeto de extensão de educação ambiental desenvolvidas nas escolas municipais e uma ONG na Cajazeiras-PB, por alunos do curso de Engenharia Civil da FSM. O projeto tem como objetivo desenvolver intervenções de educação ambiental iniciando com a conscientização e finalizando com a criação de hortas adaptadas aos espaços livres encontrados nas escolas. O projeto teve atividades realizadas durante um ano no período de Abril/2018 á Abril/2019, com as primeiras escolas escolhidas para receber o projeto, assim como a ONG, agora o projeto irá atender a mais algumas escolas, de forma a trabalhar com todas as escolas municipais, fazendo com que o município ganhe mais incentivo para melhorar a gestão ambiental do município.

A seguir, podemos ver os resultados obtidos em cada ambiente trabalhado ao longo desse ano com educação ambiental junto a crianças e adolescentes.

E.M.E.I.E.F Costa e Silva: instituição pública e urbana de ensino infantil, fundamental I e II e educação de jovens e adultos (EJA). Resultados: Desenvolver e praticar hábitos sustentáveis ajuda na preservação do meio ambiente e promove-se 
a aproximação das crianças e adolescentes com a natureza. Acredita-se que a valorização do ambiente construído será maior, promovendo a conscientização ecológica, já que as crianças de hoje serão os adultos do amanhã.

E.M.E.I.E.F Antônio de Souza Dias: instituição pública e rural de ensino infantil, fundamental I e II. Resultados: Acredita-se que, para um desenvolvimento satisfatório de práticas sustentáveis, tem que ser voltadas para atividades que prendam e chamem a atenção das crianças e adolescentes, que, além de serem uma forma viável, divertida, espera-se ao mesmo tempo que sejam educativa e influenciem a exercitar diariamente a Educação Ambiental como ações diárias e fundamentais em suas vidas. Algumas ideias foram apresentadas visando a ações para reduzir o uso desenfreado de recursos naturais como reuso de água, elaboração de hortas verticais, influenciar hábitos de reciclagem, entre outros.

E.M.E.I.E.F Luiz Cartaxo Rolim: instituição pública e urbana de ensino infantil, fundamental I e II. Resultados: A interação com crianças e adolescentes torna-se um método de aprendizagem de grande eficácia, visto que um profissional na área da engenharia civil não trabalha apenas com números e fórmulas, mas também com a interação social no meio de trabalho. E é dessa forma, interagindo, demonstrando e explicando que conseguisse despertar o interesse desses alunos para começarem a desenvolver pensamentos e ações que não prejudiquem o meio ambiente.

OSCIP Luiz Antônio Bezerra: instituição que promove o um trabalho social e acolhe e recupera crianças e adolescentes em situação de risco da cidade de Cajazeiras - PB. Resultados: o projeto, além de transmitir conhecimento, transmitiu valores, facilitando ou inibindo comportamentos e possibilita a aprendizagem de normas sociais. Puderam-se comprovar os benefícios que essa forma interdisciplinar de trabalho proporciona às crianças. Assim, desenvolve-se uma ampla conscientização da sociedade para a redução dos impactos ambientais causados pelo ser humano, visando ao desenvolvimento sustentável do planeta.

Através desse projeto, podemos despertar o interesse do público envolvido para a adoção de práticas sustentáveis que possam melhorar o ambiente que frequentam, permitindo também o engajamento ativo com o meio ambiente. 
Portanto, nota-se que o Civil Verde é um simples projeto de extensão mais com um valor social muito importante, pode ser considerado como um impulsionador do desenvolvimento sustentável dentro da sociedade cajazeirense.

Em alguns locais como obras, madeireiras, residências e os próprios laboratórios da FSM, visualizou-se um alto índice de geração de resíduos sólidos, identificando-se que esses resíduos poderiam ser reutilizados, prolongando a sua vida útil e até mesmo dando um destino adequado a eles. Nas obras, identificamos que as madeiras, após finalização da construção poderiam ser destinadas às colunas da estufa e telhado.

Os resíduos identificados nas residências que podem ser reutilizados na proposta da estufa com material convencional foram os resíduos plásticos, mais especificadamente as garrafas PETs, geradas a partir do consumo de refrigerantes, que podem ser recicladas e reutilizadas de diversas formas. Na estufa sustentável, ela será integrada e aplicada como material de coberta, a partir da sua fixação em um madeira de espessura mais fina, para melhor manuseio e fixação do material plástico ao qual exercerá a função de uma telha. As madeiras são provenientes das madeireiras, já que a venda das madeiras é realizada na metragem, o que pode levar a desperdícios de materiais por não obter o tamanho desejado do cliente, assim, solicita-se a doação desses materiais descartados para reutilização na estufa.

O óleo diesel é proveniente de oficinas mecânicas. Os óleos utilizados pelas máquinas tem certo período de uso, sendo necessário trocar por um novo para manter um bom funcionamento. Esses óleos, junto com sacolas plásticas encontradas em residências, são adequados para tratar madeiras.

Nos laboratórios de materiais da FSM, são desenvolvidas as atividades práticas do curso de Engenharia Civil, que permitem que os discentes realizem a criação de corpos de provas de concreto para teste e definição de resistência, porém está ocasionando a geração e acumulação elevada de corpos de provas, os quais, após ensaios, não possuem outra aplicabilidade, e não se sabia como destiná-los adequadamente. 
Com isso buscou-se uma solução para este problema, avaliando que esse material passado no triturador de resíduos nos permitiria utilizá-lo como agregado graúdo na base da estufa, delimitando a área executada.

Há uma indicação para que seja realizada a caracterização dos agregados graúdos a serem utilizados. Essa caracterização pode ser realizada por meio do ensaio granulométrico por peneiramento grosso, e permite classificar as dimensões do material. O peneiramento indicado é para as peneiras de 1" $(25 \mathrm{~mm})$ e 3/4" (19mm).

No comparativo realizado, analisaram-se dois métodos construtivos que podem ser empregados na execução da estufa sustentável $(X)$, e em seguida realizou-se uma análise no quantitativo financeiro entre as estufa $X$ com material convencional e estufa $Y$ com material não convencional com área de $4 \mathrm{~m}^{2}$.

Com esse levantamento de custos e resíduos, percebeu-se que o projeto civil verde pode construir ambientes para cultivar hortas, em pequenos espaços nas escolas, assim, sem ter gastos e fazendo jus ao projeto, reutilizando materiais não convencionais, dando um destino adequado aos resíduos gerados pela sociedade.

Assim, para a estufa com material convencional $(X)$, não haveria gastos financeiros, apenas necessitaria da mão de obra dos próprios discentes ligados ao projeto. A tabela 01 a seguir mostra os resíduos reutilizados na execução da estufa proposta.

Tabela 01: Orçamento para construção da estufa X com material convencional.

\begin{tabular}{l|l}
\hline Material Convencional & \multicolumn{2}{l}{ Origem/Valor } \\
\hline Madeira (barrote) $30 \times 30 \mathrm{~cm}$ & Resíduo de Obra Particular \\
\hline Madeira (Ripas) $15 \times 140 \mathrm{~cm}$ & Resíduo de Madeireira \\
\hline Garrafas Pet Plásticas & Resíduo de Residências Familiar \\
\hline Agregado Graúdo & Resíduo de Laboratório - FSM \\
\hline Sacolas Plásticas & Provenientes de compras nas Residência \\
\hline Mão de Obra & Discentes do Projeto \\
\hline Óleo diesel Usado & Oficinas mecânicas/Laboratório FSM \\
\hline Mão de Obra & Discentes do Projeto \\
\hline Custo total & $\mathbf{0 , 0 0}$ \\
\hline
\end{tabular}

Fonte: SOUZA, 2019. 
Para uma estufa de materiais não convencionais $(\mathrm{Y})$, o gasto com sua produção seria maior, por ter que realizar a compra no comercio local dos materiais para obter o material necessário. Assim, realizou-se uma cotação de preços em empresas definidas como $A$ e $B$ do comercio para uma comparação de preços, sendo realizado para 1 metro/unidade de cada item. A tabela 02 apresenta todos os itens necessários para a construção da estufa $(Y)$ e os respectivos valores em $R \$$, cotados em empresas definidas como tipo (A).

Tabela 02: Orçamento para construção da estufa $Y$ com material não convencional cotados em empresas tipo $(A)$.

\begin{tabular}{|c|c|c|}
\hline Material Não Convencional & Und & Valor (R\$) \\
\hline Madeira trabalhada (pilares/barrote) $2,00 \times 0,30 \mathrm{~m}$ & $\mathrm{~m}$ & 18,75 \\
\hline Madeira trabalhada (pilares/barrote) $2,30 \times 0,30 \mathrm{~m}$ & $\mathrm{~m}$ & 18,75 \\
\hline Madeira trabalhada (caibros) $2,50 \times 0,20 \mathrm{~m}$ & $\mathrm{~m}$ & 5,0 \\
\hline Madeira trabalhada (caibros) $2,00 \times 0,20 \mathrm{~m}$ & $\mathrm{~m}$ & 5,0 \\
\hline Madeira trabalhada (ripas) $2,20 \times 0,15 \times 0,25 \mathrm{~m}$ & $\mathrm{~m}$ & 2,5 \\
\hline Plástico para cobertura 2 × 2,5 (bobina com $8 \times 20 \mathrm{~m}$ ) & $\mathrm{m}^{2}$ & 21,53 \\
\hline Pregos $24 \times 60$ & $\mathrm{~kg}$ & 10,0 \\
\hline Pregos $15 \times 21$ & $\mathrm{~kg}$ & 10,0 \\
\hline Arrame liso galvanizado & $\mathrm{m}$ & 12,0 \\
\hline Óleo diesel Novo & Its & 3,719 \\
\hline Mão de obra (servente) & hora & 35,61 \\
\hline Custo total & & 142,66 \\
\hline
\end{tabular}

Fonte: SOUZA, 2019.

A tabela 03 apresenta todos os itens necessários para a construção da estufa $(Y)$ e os respectivos valores em $R \$$ cotados em empresas definidas como tipo (B). 
Tabela 03: Orçamento para construção da estufa $Y$ com material não convencional cotados em empresas tipo (B).

\begin{tabular}{lcc}
\hline Material Não Convencional & Und & Valor (R\$) \\
\hline Madeira trabalhada (pilares) $2,00 \times 0,30 \mathrm{~m}$ & $\mathrm{~m}$ & 22,00 \\
\hline Madeira trabalhada (pilares) $2,30 \times 0,30 \mathrm{~m}$ & $\mathrm{~m}$ & 22,00 \\
\hline Madeira trabalhada (caibros) $2,50 \times 0,20 \mathrm{~m}$ & $\mathrm{~m}$ & 5,5 \\
\hline Madeira trabalhada (caibros) $2,20 \times 0,20 \mathrm{~m}$ & $\mathrm{~m}$ & 5,5 \\
\hline Madeira trabalhada (ripas) $1,20 \times 0,15 \times 0,25 \mathrm{~m}$ & $\mathrm{~m}$ & 3,0 \\
\hline Plástico para cobertura $2 \times 2,5$ (bobina com $8 \times 20 \mathrm{~m})$ & $\mathrm{m}^{2}$ & 23,63 \\
\hline Pregos $24 \times 60$ & $\mathrm{~kg}$ & 12,0 \\
\hline Pregos $15 \times 21$ & $\mathrm{~kg}$ & 12,0 \\
\hline Arrame liso galvanizado & $\mathrm{m}$ & 13,0 \\
\hline Óleo diesel Novo & $\mathrm{lts}$ & 3,719 \\
\hline Mão de obra & hora & 35,61 \\
\hline Custo total & & $\mathbf{1 5 7 , 9 6}$ \\
Fonte: SOUZA, 2019. & &
\end{tabular}

Considerou-se o óleo diesel novo nos orçamentos, por se manter a necessidade de realizar os cuidados adequados com a matéria na parte inferior a ser cravada no solo.

Com a realização de pesquisa de preços das empresas $(A)$ e $(B)$ das tabela 02 e 03, obteve-se um preço total de $R \$ 142,86$ e $R \$ 157,96$ respectivamente, esses valores são equivalentes para execução de $1 \mathrm{~m}^{2}$ de estufa com material não convencional. Assim, para obter o valor para qualquer tamanho que se deseje construir, basta realizar uma operação. Tomando por exemplo a área proposta, analisou-se que, para área de $5 \mathrm{~m}^{2}$, o valor a ser gasto usando os materiais adquiridos na empresa (A) é de um total de $R \$ 714,30$ e na empresa (B), um total de $\mathrm{R} \$ 789,80$.

Assim, por meio da realização de um do orçamento comparativo, levando em conta a disponibilidade de materiais e mão de obra na região, e após uma análise, obteve-se uma redução de custos financeiros, sendo viável a execução e emprego da estufa sustentável nas escolas municipais da cidade de Cajazeiras-PB. 


\section{CONCLUSÃO}

O desenvolvimento desse trabalho demonstrou o quanto é relevante despertar na sociedade a importância da reciclagem, por meio da reutilização dos resíduos sólidos como uma forma de prolongando a sua vida útil. É importante compreender que atualmente vivemos uma realidade em que há a necessidade de contribuir de alguma maneira com o meio ambiente. Orienta-se ter um controle de consumo de produtos, e adquirir apenas o suficiente para suprir nossas necessidades, pois a geração futura também irá precisar de suprimentos para sobreviver.

Os desafios que existem no meio social, econômico e ambiental podem ser melhorados com a integração entre eles sendo a sociedade responsável por desempenhar os papéis mais importantes para favorecer o desenvolvimento sustentável. Dentro desse contexto, ressalta-se, ainda, a importância de o poder público municipal promover a gestão ambiental perante a sociedade, pois esse deve envolver educadores, gestores, escolas e a sociedade de uma forma geral. Inovar em termos de metodologias quanto à forma de inserir a educação ambiental nas escolas é um dos caminhos a serem trilhados para que ocorram melhorias no meio ambiente. O poder público municipal pode criar um centro de desenvolvimento coorporativo a fim de envolver a sociedade em programas voltados à educação ambiental local, como uma forma de auxiliar e melhor disseminar a conscientização ecológica.

Vale ressaltar que, diante das percepções e critérios analisados para projeção da estufa sustentável, a reutilização dos materiais recicláveis contribui para uma melhor visão sobre o meio ambiente e conduz à mudança de comportamento, especialmente, em relação à maneira crítica da sociedade perceber e passar a ver melhor os problemas enfrentados no mundo.

Logo, após avaliação da estufa, observa-se que houve uma grande economia de materiais e mão de obra, além da redução de resíduos sólidos proporcionado 
pela reutilização dos mesmos. Ela está apta a integrar o projeto de extensão do grupo Civil Verde e passar a ser construída nas escolas municipais contempladas com o projeto de educação ambiental na Cidade de Cajazeiras, a fim de atender aos espaços disponíveis nas escolas e ser um modelo padrão. Ressalta-se que a estruturação da estufa sustentável proposta a ser seguida na construção pode ser empregada em qualquer região, pois o foco está mantido na reutilização dos materiais não convencionais, visto que a produção de resíduos sólidos é um problema de contexto mundial.

\section{REFERÊNCIAS BIBLIOGRÁFICAS}

ABRECON. Associação Brasileira para Reciclagem de Resíduos da Construção Civil e Demolição. Relatório Pesquisa Setorial 2015/2016. São Paulo, 2015. Disponível em: $<$ http://abrecon.org.br/pesquisa_setorial/>. Acesso em 26 out. 2018.

ABRELPE. Associação Brasileira de Empresas de Limpeza Pública e Resíduos Especiais. Panorama dos Resíduos Sólidos no Brasil 2017. Disponível em: $<$ http://abrelpe.org.br/panorama/>. Acesso em 29 out. 2018.

ABREU, Maria das Dores de Souza. Licenciamento ambiental na Paraíba: descentralização, entraves e possibilidades. Dissertação (Mestrado em Desenvolvimento e Meio Ambiente) Universidade Federal da Paraíba. João Pessoa, 2014.

BAPTISTA JUNIOR, Joel Vieira; ROMANEL, Celso. Sustentabilidade na indústria da construção: uma logística para reciclagem os resíduos de pequenas obras. Urbe, Rev. Bras. Gest. Urbana. v. 5, n. 2, p. 27-37, 2013. Disponível em:< http://www.scielo.br/pdf/urbe/v5n2/a04v5n2.pdf>. Acesso em: 16 nov. 2018. https://dx.doi.org/10.7213/urbe.05.002.SE02.

BRANCALIONE, Leandro. Educação ambiental: refletindo sobre aspectos históricos, legais e sua importância no contexto social. Rev. Educ. Ideau. v. 11, n.23, ISSN 1809-6220, 2016. Disponível em: <https://www.ideau.com.br/getulio/restrito/upload/revistasartigos/358_1.pdf>. Acesso em 13 ago. 2018.

BRASIL. Lei $\mathbf{n}$. 12.305, de 2 de agosto de 2010. Política nacional de resíduos sólidos [recurso eletrônico]. 2. ed. Brasília: Câmara dos Deputados, Edições Câmara, 2012.

CARVALHO, Isabel Cristina de moura. Educação ambiental: a formação do sujeito ecológico. 6. ed. São Paulo: Cortez, 2012.

CERMEÑO, Z. Serrano. Construcción de Invernaderos. Madrid: Grupo MundiPrensa, 2005.

CMMAD. Comissão Mundial sobre o Meio Ambiente e Desenvolvimento. O Nosso Futuro Comum. Disponível em: < https://edisciplinas.usp.br/pluginfile.php/4245128/mod_resource/content $/ 3 /$ Nosso $\% 20$ Futuro\%20 Comum.pdf>. Acesso em 18 out. 2018

DIAS, Genebaldo Freire. Educação ambiental: princípios e práticas. 9. ed. São Paulo: Gaia, 2004. 
DIAS, Reinaldo. Gestão ambiental: responsabilidade e sustentabilidade. 1. ed. 4. reimpr. São Paulo: Atlas, 2009.

FILHO, Joaquim Alves da Costa Reestruturação Urbana de Cajazeiras - PB Influenciada Pela Implantação e Expansão do Setor de Ensino Superior. Monografia (Licenciatura em Geografia) - Universidade Federal de Campina Grande. Cajazeiras, 2015.

GIL, Antônio Carlos. Métodos e técnicas de pesquisa social. 6. ed. São Paulo: Atlas,2008.

IBAMA. O Instituto Brasileiro do Meio Ambiente e dos Recursos Naturais Renováveis. Disponível em:<http://www.ibama.gov.br/>. Acesso em: 16 nov. 2018.

IBGE. Instituto Brasileiro de Geografia e Estatística. Brasil/Paraíba/Cajazeiras. Disponível em: $<$ https://cidades.ibge.gov.br/brasil/pb/cajazeiras/panorama >. Acesso em 02 de Out. 2018.

IBGE. Portal de Mapas. Disponível em: $<$ <ttps://portaldemapas.ibge.gov.br/portal.php\#mapa118>. Acesso em 05 de out. de 2018.

LAKATOS, Eva Maria; MARCONI, Marina de Andrade. Fundamentos de metodologia científica. 5. ed. São Paulo: Atlas 2003.

MEDINA, Naná Mininni, A formação dos professores em educação ambiental. In: MEC-SEF. Textos sobre Panorama da educação ambiental no ensino fundamental. Brasília, 2000. p. 17-24. Disponível em:< http://www.dominiopublico.gov.br/download/texto/me002244.pdf>. Acesso em 22 out. 2018.

MELLO, Lucélia Granja de. A importância da Educação Ambiental no ambiente escolar. ISSN 2446-9394, 14/03/2017. Disponível em: $<$ https://www.ecodebate.com.br/2017/03/14/importancia-da-educacao-ambiental-no-ambienteescolar-artigo-de-lucelia-granja-de-mello/>. Acesso em: 16 nov. 2018.

MMA. Ministério do Meio Ambiente. Histórico Mundial. Disponível em: <http://www.mma.gov.br/educacao-ambiental/politica-de-educacao-ambiental/historicomundial.html>. Acesso em 11 ago. 2018.

MMA. Conceitos de Educação Ambiental. Disponível em: <http://www.mma.gov.br/educacaoambiental/politica-de-educacao-ambiental>. Acesso em 13 ago. 2018.

MMA. Histórico brasileiro da educação ambiental. Disponível em: <http://www.mma.gov.br/educacao-ambiental/politica-de-educacao-ambiental/historico-

brasileiro>. Acesso em 14 ago. 2018.

MMA. Agenda 21. Disponível em:<http://www.mma.gov.br/responsabilidadesocioambiental/agenda-21>. Acesso em 13 ago. 2018.

MMA. Resolução CONAMA no 307, de 5 de julho de 2002 Disponível em:<http://www2.mma.gov.br/port/conama/legiabre.cfm?codlegi=307>. Acesso em 22 out. 2018.

MORADILLO, Edilson Fortuna de; OKI, Maria da Conceição Marinho. Educação ambiental na universidade: construindo possibilidades. Quím. Nova. v. 27, n. 2, p. 332-336, abr. 2004. Disponível em: <http://www.scielo.br/scielo.php?script=sci_arttext\&pid=S01000422004000200028\&lng=pt\&nrm=iso>. Acesso em: 12 out. 2018.

MORALES, A. Góis. 2004. Educação Ambiental em Busca de uma Sociedade Sustentável. Disponível em: <www.amigosdanatureza.org.br >. Acesso em: 16 nov. 2018.

MORGADO, F. S.; SANTOS, M. A. A. A Horta Escolar na Educação Ambiental e Alimentar: 
Experiência d Projeto Horta Viva nas Escolas Municipais de Florianópolis. Revista Eletrônica de Extensão. v. 5, n. 6, p. 1-10, 2008. Disponível em: <https://periodicos.ufsc.br/index.php/extensio/article/view/9531>. Acesso em 27 out. 2018. https://doi.org/10.5007/\%25x.

PLANALTO. Constituição brasileira. Lei № 9.795, de 27 de abril de 1999. Disponível em: <http://www.planalto.gov.br/CCIVil_03/LEIS/L9795.htm>. Acesso em 15 ago. 2018.

REA. Rede de Educação Ambiental na Paraíba. Disponível em: <http://www.prac.ufpb.br/reapb/historia.html>. Acesso em 27 ago. 2018.

REISSER JUNIOR, C.; REICHERT, L. J. Construção de estufa modelo capela. Pelotas: Embrapa Clima Temperado, 1998. $21 \mathrm{p}$.

SEMAM. Secretaria de Meio Ambiente. João Pessoa tem mais de 1,1 mil denúncias de crimes ambientais. Disponível em: <https://g1.globo.com/pb/paraiba/noticia/joao-pessoa-temmais-de-11-mil-denuncias-de-crimes-ambientais-diz-semam.ghtml> Acesso em: 16 nov. 2018. 